IZA DP No. 7630

Sanctions for Young Welfare Recipients

Gerard J. van den Berg Arne Uhlendorff Joachim Wolff

September 2013

Forschungsinstitut zur Zukunft der Arbeit Institute for the Study of Labor 


\title{
Sanctions for Young Welfare Recipients
}

\author{
Gerard J. van den Berg \\ University of Mannheim, \\ IFAU Uppsala and IZA \\ Arne Uhlendorff \\ University of Mannheim, \\ IAB Nuremberg, DIW Berlin and IZA
}

Joachim Wolff

IAB Nuremberg

\section{Discussion Paper No. 7630 \\ September 2013}

\author{
IZA \\ P.O. Box 7240 \\ 53072 Bonn \\ Germany \\ Phone: +49-228-3894-0 \\ Fax: +49-228-3894-180 \\ E-mail: iza@iza.org
}

\begin{abstract}
Any opinions expressed here are those of the author(s) and not those of IZA. Research published in this series may include views on policy, but the institute itself takes no institutional policy positions. The IZA research network is committed to the IZA Guiding Principles of Research Integrity.

The Institute for the Study of Labor (IZA) in Bonn is a local and virtual international research center and a place of communication between science, politics and business. IZA is an independent nonprofit organization supported by Deutsche Post Foundation. The center is associated with the University of Bonn and offers a stimulating research environment through its international network, workshops and conferences, data service, project support, research visits and doctoral program. IZA engages in (i) original and internationally competitive research in all fields of labor economics, (ii) development of policy concepts, and (iii) dissemination of research results and concepts to the interested public.
\end{abstract}

IZA Discussion Papers often represent preliminary work and are circulated to encourage discussion. Citation of such a paper should account for its provisional character. A revised version may be available directly from the author. 
IZA Discussion Paper No. 7630

September 2013

\section{ABSTRACT}

\section{Sanctions for Young Welfare Recipients ${ }^{*}$}

Social welfare systems usually imply specific obligations for benefit recipients. If a recipient does not comply with these obligations, a sanction involving a punitive benefits reduction may be imposed. In this paper we give an overview of the literature on the effects of sanctions in social welfare systems and we present first results on the effects of sanctions for young unemployed welfare recipients based on German administrative data. The German welfare system is particularly strict for young individuals. We distinguish between mild and strong sanctions and we focus on the impact of these sanctions on job finding probabilities. Our results suggest that each type of sanction leads to an increased transition rate to work, and that this effect is higher for strong sanctions. However, strong sanctions for young welfare recipients involve a complete withdrawal of the basic cash transfer payments, and there exists evidence that these severe sanctions might go along with additional, negative effects for sanctioned individuals.

JEL Classification: J64, J65, I38, C41

Keywords: monitoring, welfare, youth unemployment, duration models, unemployment benefits, social assistance

Corresponding author:

Gerard J. van den Berg

Department of Economics

University of Mannheim

L7, 3-5

68131 Mannheim

Germany

E-mail: gjvdberg@xs4all.nl

\footnotetext{
* We thank Johan Vikström, Michael Svarer and participants at the 2013 NEPR conference on "Youth and the labor market" for helpful comments.
} 


\section{Introduction}

Being on welfare for a long period has adverse effects on future employment prospects. At the early stages of the working career, a long welfare spell may lead to the loss of cognitive human capital skills as well as non-cognitive skills such as work motivation and discipline. Therefore, the activation and reintegration of young welfare recipients is an important policy goal in many European countries. In this context, monitoring and sanctions are a central policy tool. Social welfare systems usually define specific obligations for unemployed benefit recipients. If a recipient does not comply with his or her obligations, benefit rules may stipulate the imposition of a sanction. For example, for unemployed welfare recipients in Germany sanctions can be imposed if the benefit recipient refuses a job opportunity or the participation in active labor market policy programs, or if the benefit recipient missed an appointment with the caseworker. By setting an incentive to comply with such job search requirements the intention is to combat moral hazard and to increase the transition rate from welfare to work.

The German welfare system allows for mild and strong sanctions. The main reason for a mild sanction is the missing of an appointment with the caseworker, whereas the refusal to search for a job or to participate in a training program may lead to a strong sanction. Both types of sanctions usually imply a reduction of the benefit payments for three months, but they differ with respect to the size of the reduction. Strong sanctions are particularly severe for young welfare recipients. As a rule, they involve a complete withdrawal of welfare for up to 3 months, apart from payments for rent and heating. The underlying idea is that the threat of such a sanction induces young welfare recipients to leave welfare as quickly as possible. Thus, these young welfare recipients have on the one hand a higher probability of participating in active labor market programs while on the other hand they are sanctioned more strongly if they do not comply with benefit rules. In contrast to this, mild sanctions do not differ between recipients below and above 25 years of age. For both age groups they amount to a reduction of the basic cash benefit payments by 10 percent.

Economic job search models that incorporate sanctions in unemployment explicitly predict a faster transition rate to work once a sanction is imposed. This is because the 
reservation wage tends to fall and the search intensity tends to rise. This prediction has been confirmed in a number of studies (see the overview in Section 2). There additionally exists evidence that an increased sanction probability leads to an increased probability of leaving the labor force and the welfare receipt (see e.g. McVicar and Podivinksy 2009). Moreover, evidence based on qualitative surveys among caseworkers and young sanctioned individuals for Germany suggests that strong sanctions might have adverse effects and for example lead to low paid and unstable jobs or increase debt problems and have a negative impact on nutrition (Götz, LudwigMayerhofer and Schreyer, 2010, and Schreyer, Zahradnik and Götz, 2012).

In this paper we examine the effects of sanctions on the transition rate to work among young welfare recipients. We study the inflow into "welfare without employment" during the period of January 2007 to March 2008. Our sample is drawn from administrative records. It is restricted to welfare recipients aged 18 to 24 years and to their first welfare spell during this observation window. The analysis is based on a sample of about 72,000 young men in West Germany. The majority of the individuals in our sample are singles without children. In Germany, the welfare level for individuals in this group is low compared to Nordic countries like Sweden and Denmark, and it is also lower than in the Netherlands (Immervoll, 2009). We argue that the monitoring system in Germany is special in the sense that it is unusually strict, with sometimes severe sanctions, and a high sanction rate.

Broadly speaking, our contribution to the literature on sanctions is twofold. ${ }^{1}$ First, no previous study has focused on young welfare recipients, who are vulnerable in the current economic crisis and who may constitute a "lost generation" if they do not move to work in the near future. Second, we jointly analyze the impact of mild and strong sanctions on the transition rate to work.

The empirical analysis takes the dynamic selection of young welfare recipients into the treatment into account by applying the "timing of events approach" following Abbring and van den Berg (2003). This approach allows controlling for selection into treatment based on observed and unobserved characteristics. We are interested in the impact of two types of

\footnotetext{
${ }^{1}$ See Section 2 for a literature overview.
} 
imposed sanctions on the probability of leaving unemployment for a job. Therefore, we jointly estimate the hazard rate to mild sanctions, to strong sanctions and to unsubsidized work.

Similar to other studies on the effect of sanctions on the transition rate to work, the effects we find are significantly positive. Perhaps more interesting are the magnitudes of the effects we find. In particular, it is interesting to compare the estimated effects of the two types of sanctions with each other. From a forward-looking individual's point of view, once a sanction has been given, it is irrelevant why the sanction was given. What matters are the benefits reduction and the increased exposure to future monitoring after a detection. If the estimated effects are not very different for different sanction types then we conclude that the effects are mostly driven by the fear of increased monitoring. If the effect of a strong sanction is much larger than the effect of a mild sanction then we conclude that the effect is mainly driven by the benefits reduction. These inferences are relevant from a policy point of view. If the effect is mostly driven by the monitoring threat then it is preferable to use mild sanctions for any violation, at least in case of a first punishment during a welfare spell. Van den Berg and Vikström (2013) argue that mild sanctions may be easier to apply by case workers if they have a personal bond with their clients, as is the case in e.g. Sweden. We shall see below that the same applies to case workers of welfare recipients in Germany.

The paper is organized as follows: Section 2 provides an overview on the previous literature on sanctions in social welfare systems. Section 3 describes the institutional background in Germany. Section 4 presents the administrative data and descriptive statistics. Section 5 describes the econometric approach. The results of the empirical analysis are presented in Section 6, and Section 7 concludes.

\section{Previous evidence on the effects of sanctions in social welfare systems}

There exist only a few studies on the effectiveness of sanctions in social welfare systems. In the following, we give a brief overview of the main empirical results, whereby we focus on European countries. We start by presenting results of quantitative studies based on data from Germany 
and the Netherlands, before we discuss the results of two qualitative studies on sanctions in the German social welfare system. ${ }^{2}$

An early study on the effectiveness of sanctions for welfare recipients is provided by van den Berg, van der Klaauw and van Ours (2004). The analysis is based on an inflow sample into welfare benefit receipt in Rotterdam. Based on this inflow sample, the authors estimate timingof-events-models. The duration and size of benefit reductions are rather low: most welfare sanctions are for 1 to 2 months and the maximum reduction of the welfare benefit is 20 percent. The results suggest a strong increase of the hazard rate from welfare to work $(+148 \%)$. The authors investigate effect heterogeneity with respect to age. Their results suggest that the sanction effect varies over different age-intervals. The lowest point estimate for the sanction effect was found for unemployed workers aged below 26 years and the highest for those aged between 55 and 65 years. However, the effects of these two groups are not statistically different from each other.

Based on a more recent inflow sample into to welfare receipt from the same municipality, van der Klaauw and van Ours (2012) compare the effects of re-employment bonuses and benefit sanctions on the exit rates from welfare to work. While they do not find a significant impact of re-employment bonuses, their results indicate a positive impact of sanctions on the job-finding probability. Compared to the study of van den Berg, van der Klaauw and van Ours (2004) their estimates suggest a relatively small increase by 21 percent for men and 47 percent for women. They argue that the increased use of sanctions compared to the 1990s may have reduced the effectiveness and may explain the difference in the effect sizes. They do not find any evidence for different effects depending on the age-group of the welfare recipients when they regard men. However, for women the sanction effect considerably increases over four age intervals $(<25,25$ -

\footnotetext{
2 There additionally exist a number of studies analyzing the impact of sanctions in unemployment insurance systems, see, e.g., Abbring, van den Berg and van Ours (2005), Lalive, van Ours and Zweimüller (2005), Svarer (2011), Cockx et al. (2011), Roed and Westlie (2012), van den Berg and Vikström (2013), Arni, Lalive and van Ours (2013), and van den Berg, Hofmann and Uhlendorff (2013). These studies usually find that sanctions increase the probability of leaving unemployment for a job. Some of the studies additionally investigate the impact on job match quality, and their results suggest that jobs found after the imposition of a sanction go along with lower wages and are less stable.
} 
$34,35-44$, and 45 to 54 years) and then falls sharply for those aged at least 55 years. However, only one of the differences is statistically significant at the $10 \%$ level.

There exist several studies on the impact of welfare benefit sanctions in Germany. Schneider (2008 and 2009) uses matching methods to analyze survey data on the job search behavior and employment outcomes based on a survey of people who received welfare at the start of the year 2005 and who were interviewed at the end of 2005 or the start of 2006 . Her results indicate no well-determined effects of benefit sanctions on reservations wages or search effort of welfare recipients, but partially positive effects on their regular employment rate. One reason for not finding any effects on the first two outcomes might be that these variables are not available for the time period directly after the sanctioning, but just at the interview dates. Her sample includes young welfare recipients. However, the effectiveness of sanctions is not analyzed separately for this group.

Boockmann, Thomsen and Walter (2009) investigate 154 (out of 439) German job centers. A job center is a local welfare agency, which is for example responsible for the provision of welfare benefits and of active labor market policy programs for welfare recipients. Their analysis is based on combined data from a survey of welfare recipients conducted in two waves (at beginning of 2007 and about one year later) and administrative records. Moreover, they match survey data on activation strategies of the 154 job centers to the individual data. They study sanction effects by an instrumental variable approach: individual sanctions are either instrumented by the job centers' sanction strategies as reported by their managers or by their actual sanction rates. Based on linear models they estimate the impact of sanctions on employment and welfare receipt separately for the first 8 months after a first sanction was imposed. Their results point towards a reduction of the probability of welfare receipt and a rise of the employment rates due to intensified sanctioning. The authors do not investigate effect heterogeneity with respect to age.

In a more recent study Hillmann and Hohenleitner (2012) analyze the effects of welfare benefit sanctions based on the household panel survey PASS (Labor Market and Social Security). The authors apply a timing-of-events approach and find positive effects of imposed sanctions on 
the probability of leaving welfare for work. However, the first wave of the PASS data consists of a stock-sample of households being on welfare giving retrospective information about previous sanctions. This sampling scheme has to be taken into account for the estimation of duration models and it implies that it is hard to interpret the results of a model which is based on the assumption of having an inflow sample into the state of interest, in this case the welfare receipt.

\section{Qualitative evidence on the effectiveness of sanctions for young welfare recipients}

Götz, Ludwig-Mayerhofer and Schreyer (2010) analyze a qualitative survey conducted in 11 job centers in Germany. 26 caseworkers or other persons responsible for welfare recipients and sanctions were interviewed between October 2007 and April 2009. The interviews suggest a relatively positive view of the caseworkers on mild sanctions. They can lead to a more reliable behavior of sanctioned welfare recipients in the future. Strong sanctions lead to a withdrawal of the basic cash benefit, while the benefit to cover the costs of accommodation and heating remains untouched. The caseworkers seem to be rather skeptical about the effectiveness of this type of sanctions. Some of them reported examples of severe sanctions that apparently altered the welfare recipients' behavior in a desirable way. However, caseworkers often assessed critically that the entire benefit to cover daily expenses is withdrawn. In particular the sanctions might have no impact on the behavior of drug addicts or people with alternative sources of income, e.g., when working in the shadow economy. Moreover, as far as welfare recipients change their behavior, the strong sanctions might induce them to accept quickly any kind of job available. The caseworkers stress potential adverse consequences for the sanctioned individuals, e.g. if they accept jobs that are low paid, unstable and that provide too little training for people at the beginning of their career. Repeated strong sanctions within one year imply a temporary loss of the entire welfare benefit. Only four of the interviewed caseworkers regarded these sanctions as appropriate. The other respondents were more critical and rather interpreted them as a tool for extreme situations, e.g., if welfare recipients refuse any kind of cooperation. According to the analysis, two main reasons explain that caseworkers have a relatively hostile view of these sanctions. Their social conscience is one of them. Another reason is that the very severe sanctions can cause harm that makes it more difficult to achieve the key goal of reducing 
or ending the benefit recipients' welfare dependency, in particular by integrating them into work. E.g., if the sanctioned people can no longer afford their accommodation and have to move out, they do not get closer to the goal of reducing or ending welfare benefit. It may rather become more difficult to reach this goal.

In a related study, Schreyer, Zahradnik and Götz (2012) conducted a survey in one selected job center. They interviewed young welfare recipients with at least one imposed strong sanction in the past. 10 male and 5 female welfare recipients took part in this survey during the period of May to November 2010. Their results indicate that many of the sanctioned respondents come from families that were abandoned early by their father. The mothers of some of them had severe health problems and some of the respondents talked about experiences of violence and/or imprisonment. All of them were characterized by a discontinuous education and employment history. About ten faced repeated sanctions and lost (temporarily) their entire welfare benefit. The results suggest that sanctions lead to restricted nutrition in the sense of decreased spending on healthy and fresh food. However, none of the respondents reported hunger as a consequence of sanctions. With respect to their accommodation four respondents who faced a (temporary) complete withdrawal of their welfare benefit could no longer pay bills of electric power suppliers. As a consequence the suppliers blocked their services. Moreover, four sanctioned respondents lost their apartments and had to move temporarily into a host of the homeless. Many of the respondents reported that sanctions increased their debt problems. Moreover, the responses provided some indication that due to the sanction welfare recipients took up jobs without declaring them to the welfare agency or engaged in criminal activities in order to earn some money. Moreover, the analysis points out that sanctions can negatively affect psychosocial well-being and social inclusion. Overall, the results indicate that strong sanctions might go along with negative effects on the sanctioned individuals, which are usually not captured in studies focusing on the duration until finding a job and the corresponding quality of this job. 


\section{Institutional settings in Germany}

This section describes the German welfare system, the Social Code II, and its sanction rules. The Social Code II was introduced at the start of the year 2005. With its introduction two former means-tested benefits, the earnings-related unemployment assistance (UA) benefit and the flat rate social assistance (SA) benefit were replaced by a new (mostly) flat rate benefit, the unemployment benefit II. Households whose other sources of income are insufficient to achieve a minimum standard of living are eligible for the benefit. With the reform a considerable move of the welfare system towards activating welfare recipients was implemented (see e.g. Hohmeyer and Wolff 2012).

Since the reform in 2005, in principle, all members of a welfare recipient household who are capable of working are obliged to contribute to the goal of reducing the welfare dependency of their household by taking up employment. They should engage in job search and participate in active labor market programs (ALMPs). The Public Employment Service (PES) is supposed to support welfare recipients in their job search and to assist them with suitable ALMPs. The actions that should be taken by a welfare recipient and by the PES to improve a welfare recipient's perspectives in the labor market are documented in an individual action plan. The PES should sanction welfare recipients, who do not comply with their obligations without good cause. In the following we focus on key features of the welfare system that are relevant to our analysis and on its rules that were in force in the period under review of the years 2007 to 2009 .

\section{The German welfare benefit system during the years 2007 to 2009}

During 2007 and 2009 on average about five million people aged at least 15 years and who are capable of working received the unemployment benefit II (see Table 1). That amounts to roughly one tenth of the German population aged 15 to 64 years. Less than one fifth of the welfare recipients were aged younger than 25 years. About two thirds of them lived in West Germany.

[Table 1 about here]

The means-tested welfare benefit consists of several components. There is a basic cash benefit to cover a minimum level of regular expenditures of a welfare recipient apart from costs 
of rent and heating (Regelleistung zur Sicherung des Lebensunterhalts). At the beginning of the year 2007 the benefit amounted to 345 Euro a month for singles, lone parents or a person whose partner was younger than 18 years. It was 80 percent of this amount for additional household members aged at least 15 years who were capable of working. ${ }^{3}$ In a couple household of two adult partners, each partner received 90 percent of this amount. For household members who were not capable of working, the benefit was 60 percent of 345 Euro if a household member was younger than 15 years and 80 percent for household member aged at least 15 years. During the period 2007 to 2009, the basic level of this benefit was raised each year in July and reached a level of 359 Euro in July 2009.

Another component of the welfare benefit is provided to cover costs of accommodation and heating. There is no general upper limit for this benefit, but job centers determine it by regarding the relevant factors like the size and composition of the household, the size of the apartment, rents excluding cost of heating and the relevant local rent levels, which can vary considerably over different municipalities. In the period under review the job centers also provided an allowance to cover contributions to the old age pension, compulsory long-term care and health insurance. There are various other temporary components of the welfare benefit: Some allowances are available to finance temporary needs, e.g., like costs related to pregnancy or costs for changing accommodation. Moreover, until the start of the year 2011 a temporary benefit was granted to welfare recipients who exhausted their unemployment insurance (UI) benefit during the last two years.

Immervoll (2009) provides some indicators that characterize the generosity of minimum-income like the one just described in 29 OECD countries for households with no other sources of income. He presents estimates of the benefit levels relative to the median household income for one person households, single parent households with two children and for married couples with two children in the year 2007. For the latter two household types, in Germany, the benefits (including benefit for housing costs) amount to more than 55 percent of the median

\footnotetext{
3 The Social Code II regards people aged 15 to 64 years as capable of working, if they are able to work at least three hours per day.
} 
household income. Only few countries are more generous. In most countries these benefits make up for less than 50 percent of the median household income for these two household types. The benefits for single person households in Germany are far less generous, both in comparison to those for the other household types and from an international perspective. In Germany, they account for about 45 percent of median household income of this household type. This is particular relevant for our purposes because this household type comprises most of our population of interest.

\section{Punitive sanctions for welfare recipients}

The benefit rules specify several obligations for welfare recipients. They should not miss appointments with job center staff or an appointment for a necessary medical examination. The other obligations are mainly concerned with incentives to search for work or improving the job finding perspectives of welfare recipients. Welfare recipients who are capable of working, are expected to provide sufficient effort on job search, participate in suitable ALMPs that should enhance their job finding perspectives, and accept suitable job offers. Moreover, they have to discuss and sign an individual action plan with their job center and have to comply with the requirements specified in the individual action plan. Finally, they should not deliberately reduce other sources of income than welfare or available assets, in order to remain or become eligible for welfare or raise their welfare benefit. If they do not comply with their obligations without good cause, a punitive sanction should follow. The duration of a sanction is fixed to three months; for welfare recipients aged less than 25 years the sanction period may be reduced to six weeks. ${ }^{4}$ During any sanction period a welfare recipient, provided he was eligible to it, did not receive the temporary benefit available in the two years after running out of UI.

The infringements against the obligations are divided into two broad categories that lead to different benefit cuts. The first broad category consists of missing an appointment with the job center or for a medical or psychological examination. A first noncompliance leads to a

\footnotetext{
${ }^{4}$ Case-managers can reduce the length of the sanction period under certain circumstances, e.g., if a young welfare recipient refuses a job offer, but convincingly demonstrates that he is available for work or if the welfare recipient is underage and was not fully aware of the consequences of his non-compliance.
} 
reduction of the welfare benefit by 10 percent of the full basic cash benefit to cover regular expenditures of a welfare recipient apart from costs of rent and heating. Thus, in (the first half of) the year 2007 the reduction would have been 34.5 Euro for a single, even if he did not receive the full 345 Euros cash benefit because he already achieved some earnings. Such a sanction therefore lowers the total sum of the benefit components. If welfare recipients are not yet 25 years old, the benefit component to cover accommodation and heating cannot be reduced by the first sanction. Repeated infringements of the same type within one year implied higher sanctions: The sanction is then determined by the amount of the last sanction plus an additional reduction by 10 percent of the basic full cash benefit.

The second broad category includes all other possible infringements. These mainly concern direct efforts to search for work and to improve job-finding perspectives. The share of sanctions due to reducing deliberately other sources of income than welfare or available assets are negligible. ${ }^{5}$ The consequences of non-compliance differ between welfare recipients aged at least 25 and those aged below 25 . The former face a reduction of 30 percent of the basic full cash benefit for their first infringement. A second infringement within one year doubles the sanction. ${ }^{6}$ Any further repeated infringement within one year leads to a full (temporary) benefit loss. In contrast, welfare recipients aged younger than 25 years face more severe sanctions. Already in case of a first non-compliance of this type their welfare benefit is limited to the component that covers costs of rent and heating. Any further infringement out of this second broad group of sanction reasons within a period of one year implies a full loss of the welfare benefit for three months. To sum up, sanctions against welfare recipients aged younger than 25 years are particularly severe.

Table 2 shows the annual averages of the percentage of welfare recipients with at least one sanction. The share of sanctioned welfare recipients is around 2.5 percent is quite stable

\footnotetext{
${ }^{5}$ In our observation period, they make up for around one percent of the sanctions due to infringements that belong to this second broad category (Source: Statistics Department of the Federal Employment Agency).

${ }^{6}$ Provided that the benefit sanction exceeds 30 percent of the full cash benefit, the job centers can provide non-cash benefits in particular food stamps to sanctioned welfare recipients. However, no official data are available that describe how frequently sanctioned welfare recipients receive such non-cash benefits.
} 
over the years 2007 to 2009. In the West it is slightly higher than in the East. For men the proportion of sanctioned welfare recipients ranges from 3.4 to 3.6 percent and is more than twice as high as for women. The share of sanctioned individuals is with 3.8 to four percent the highest among young welfare recipients below the age of 25 years. In contrast, welfare recipients aged at least 50 years are very rarely sanctioned. Table 3 displays the monthly average number of new sanctions in relation to the average annual stock of welfare recipients in Germany. In contrast to Table 2 it distinguishes between the two broad categories of sanctions due to missing an appointment and sanctions due to any other infringement. The monthly rate of new benefit sanctions due to missing an appointment ranges from 0.66 to 0.71 percent in the years 2007 to 2009 . There are fewer sanctions related to all other infringements. The flow rate for the stronger sanctions is about 0.5 to 0.6 percent; in the West it is about 1.3 to 1.5 times as high as in the East. This reflects that the unemployment rate in the West is considerably lower than in the East and hence the scope for sanctioning welfare recipients due to insufficient job search or the refusal of placement proposals is higher.

[Tables 2 and 3 about here]

Currently, no aggregate sanction statistics are available that allow to describe these flow rates for different age groups. However, Wolff and Moczall (2012) analyzed for different sociodemographic groups of welfare recipients the empirical transition rates into the first sanction due to missing an appointment and into the first sanction due to other reasons. Their estimates show that for both types of sanctions, the transition rates of welfare recipients aged 16 to 24 years are usually far higher than those of welfare recipients from older age groups. A major reason for this is that with the introduction of the new welfare regime in 2005 they were defined as a special target group. In particular the Social Code II expects that job centers place young welfare recipients immediately into work, training or work opportunities. Nivorozhkin and Wolff (2012) show that over the period 2005 to 2010, unemployed welfare recipients aged 20 to 24 years are characterized by an inflow rate into One-Euro-Jobs, the main work opportunity scheme, of 5.3 to 6.5 percent. In contrast, the corresponding numbers for unemployed welfare 
recipients aged 25 to 29 years are lower than two percent. They find somewhat less pronounced but still high differences for the inflow rates into other ALMPs.

The procedure of imposing a benefit sanction consists of several steps. In general the job centers have to make sure that welfare recipients are aware of the potential reasons for a benefit sanction and of their consequences. If the job center observes that a welfare recipient does not comply with a benefit rule, the case-manager has to document the infringement and the job center sends a written notification to the welfare recipient. It contains the details of the noncompliance and its consequences. Moreover, it contains an answer form, with which the welfare recipient can report a good cause for the potential non-compliance, as well as the date until which the job center has to receive the response. The rules do not specify how much time has to be available for such a response. However, our administrative micro data provide the date of non-compliance and date when the sanction begins and suggest that welfare recipients often might have about one to three weeks to return the response form. If the welfare recipient does not or cannot provide some good cause, the sanction against a welfare recipient comes into force on the first day of the calendar month that follows the month in which a welfare recipient had to hand in the answer form to the notification letter.

The benefit rules envisage an imposition of a sanction, if a welfare recipient does not comply with his obligations. Nevertheless, there might be various reasons why sanctions are not automatically imposed. First of all, not all infringements are fully observed, such that a sanction can be imposed without some doubt about the non-compliance and hence without risking to lose a lawsuit at a Social Court. Moreover, job center staff with a huge workload might have insufficient time to monitor welfare recipients with the same intensity or provide them with the same intensity with job offers or ALMP placement proposals, even if they are similar in terms of their characteristics. Furthermore, caseworkers might have some discretion with respect to imposing a benefit sanction, as the Social Code II does not entirely specify what constitutes a good cause for not following some of the obligations. They have some degree of freedom to decide whether personal reasons that a welfare recipient provides, in order to justify a suspected non-compliance, constitute a good cause. Finally, an observed refusal might not lead 
to a benefit sanction, if the job center staff did not inform a welfare recipient about the consequences of a refusal or if there is some doubt that the welfare recipient was properly informed about them.

\section{Data and descriptive statistics}

Our analysis is based on German administrative data that the Institute for Employment Research makes available for scientific use. These data offer a number of relevant variables on welfare recipients and their households that allow estimating the effects of benefit sanctions on transition rates from welfare receipt without employment to unsubsidized employment. We combine information of two databases: the Integrated Employment Biographies (IEB) and the Unemployment Benefit II History Records.

The IEB contain spell data on contributory and minor employment as well as different types of benefit receipt, registered unemployment and job search, and ALMP participation. All spell information provides the exact day when the spell starts and ends. These data are informative about a number of personal characteristics like birth date, sex, nationality, highest schooling and occupational degree, place of residence (of the individual, employers, labor agencies and job centers) and disability. The Unemployment Benefit II History Records provide more detailed information on welfare recipients. They contain a household identifier. Therefore with these data we know the composition of a welfare recipient household, the role of different household members in such a household, their marital status and whether they are considered as capable of working. The Unemployment Benefit II History Records are informative about the (monthly) amount of each component of the unemployment benefit II that a welfare recipient is entitled to. Additionally, there is information on their earnings and other sources of income. Finally, these data record punitive sanctions, including the day when a sanction started and ended, the day when some non-compliance took place, the type of non-compliance, and the time period within which another sanction is regarded as a multiple sanction that leads to a higher benefit reduction. There is, however, no information on warnings, since the administrative 
processes of the job centers only imply a systematic documentation of sanctions that came into force.

Our sample is based on an inflow sample into welfare of men aged 18 to 24 years during the period January 2007 to March 2008. We limit our analysis to West Germany, since the unemployment rate in West Germany is considerably lower than in East Germany. Compared with the East in the West there is much more scope for job centers to place welfare recipients into jobs or into vocational training. Therefore, it is also much more likely that young welfare recipients are sanctioned because of refusing such offers or because of insufficient search effort. We focus on male job seekers. For the primary caretaker of children below age three, job search requirements are different. Since this concerns more often women than men, (endogenous) fertility - if not accounted for - might bias the estimated effects of sanctions. In line with this, Wolff and Moczall (2012) show that the sanction rates of mothers of children aged less than three years are close to zero, while this is not the case for fathers of very young children; in West Germany the estimated empirical sanction hazards of fathers of very young children are quite similar to those of childless single men. Therefore, focusing on men in West Germany keeps the estimated model manageable and leads to a relatively homogenous estimation sample.

We restrict the sample to individuals who at the beginning of their spell are registered as job seekers, are not working in a contributory job or participating in selected ALMPs. The selected ALMPs comprise a start-up subsidy and longer term training programs. During their welfare spells individuals might work in minor employment. Moreover, our spell definition does not exclude that they participate in short-term training, as such a participation lasts for some days up to three months only, or participate in the workfare scheme, One-Euro-Jobs. Both programs imply that welfare recipients continue with their job search. In particular, One-EuroJobs are in nearly all cases part-time jobs, in order to leave some room for welfare recipients to continue with their job search. We do not consider individuals who were already subject to some benefit sanction at the start of their spell. A major reason for this is that at the start of their spell or just before their spell they still received UI benefit and have been sanctioned due to noncompliance to the UI benefit rules and the sanction period has not ended yet. In such a case they 
are also automatically sanctioned under the welfare benefit rules at the time when they claim welfare. Finally, we discarded individuals who at the start of their welfare spell still received UI benefit. For them the consequences of some non-compliance to benefit rules without good cause do not only lead to a punitive sanction under the welfare benefit system. They are also subject to a loss of their UI benefit for some weeks.

We have to exclude from our data welfare recipients in 50 West German job centers for which micro data on sanctions is currently not available. These job centers are entirely run by municipalities and not jointly with local labor agencies. In the years 2007 to 2009 about 13 percent of (the stock of) unemployed welfare recipients were registered in these job centers in West Germany (Source: Statistics Department of the Federal Employment Agency).

Our final sample consists of 71,667 spells of male welfare recipients. We right-censor spells at the time when a welfare recipient reaches the age of 25 years, since the sanction rules change with reaching this age threshold. We analyze transitions into unsubsidized contributory employment. To exclude low-income jobs, we determine a minimum income of 500 Euro per month. However, individuals with an unsubsidized job might still receive additional welfare payments, if their wage is (still) below the legal minimum subsistence level.

[Table 4 about here]

Table 4 displays the share of exits into the first strong and first mild sanction. Around 13 percent of our observations receive a strong sanction during their welfare spell. The share of individuals with a mild sanction is slightly lower (around 12 percent). More than one third of the individuals who receive a strong sanction also receive at least one mild sanction during their welfare spell. The same holds for the mild sanctions: around 39 percent of the individuals with a mild sanction receive at least one strong sanction during their welfare spell. For around one third of the welfare spells we observe a transition into an unsubsidized job. The table additionally indicates that among the sanctioned individuals the share of individuals entering an unsubsidized contributory job is lower than for those people who were not sanctioned. This holds for strong and for mild sanctions, and it might be explained by the dynamic selection into 
the treatments: those with relatively low job finding perspectives stay longer in welfare and might be sanctioned with a higher probability.

Figure 1 plots the transition rates into a first strong sanction against spell length. The transition rate is sharply increasing at the beginning of the welfare spells and afterwards it tends to fall over time spent in welfare. The same holds for the mild sanctions (see Figure 2). Figure 3 displays the empirical transition rate from welfare to work and suggests a negative duration dependence, i.e., a decreasing job finding probability with respect to elapsed time spent in social welfare. However, this might at least partly be explained by a sorting over time; individuals with observed and unobserved characteristics, which go along with a low transition probability to employment, stay longer in welfare.

[Figures 1, 2 and 3 about here]

Table 5 displays sample averages of a selection of characteristics for the non-sanctioned and sanctioned welfare recipients. The statistics refer to the characteristics at the start of the welfare spells in our sample. For example, the sanctioned welfare recipients tend to be younger than those not facing a sanction. Moreover, the share of individuals who are below 20 years old is higher among the individuals who experience a strong sanction during their welfare receipt than among those who experience a mild sanction. Sanctioned individuals are also more frequently singles, of German nationality and they have on average a lower skill level.

[Table 5 about here]

\section{Empirical Approach}

We are interested in measuring the causal impact of the imposition of mild and strong sanctions on the duration of welfare receipt until taking up unsubsidized employment. Treated and untreated individuals might differ with respect to observed and unobserved characteristics. In order to measure the causal effects of strong and mild sanctions, we have to control for the selection process over time. We apply the "timing of events" approach (Abbring and van den Berg, 2003) - which is the standard approach in the literature on sanction effects - to a setting with two treatments, i.e., we estimate a mixed proportional hazard rate model with two dynamic 
treatments and one destination state. Transitions to alternative states like "out of labor force" are treated as independent right-censoring.

We observe an inflow sample into welfare receipt. We assume that all individual differences in the probability of finding a job at time $t$ can be characterized by observed characteristics $x$, unobserved characteristics $V_{e}$, and a sanction effect $\alpha$, if a sanction has been imposed before $t$. Also the duration until a strong and a mild sanction depends on observed characteristics $x$, the elapsed time $t$ spent in social welfare, and unobserved characteristics $V_{s}$ and $V_{m}$, respectively. We specify the transitions rate from welfare receipt without employment to a job $\theta_{e}(t)$ and the transition rates into a strong and a mild sanction $\theta_{s}(t)$ and $\theta_{m}(t)$ flexibly as piecewise constant exponential hazard rate models:

$$
\begin{aligned}
& \theta_{e}(t)=\exp \left(\sum_{j=2}^{J} I_{j}(t) \lambda_{j e}+x^{\prime}{ }_{t} \beta_{e}+I_{s}\left(t>t_{s}\right) \alpha_{s}+I_{m}\left(t>t_{m}\right) \alpha_{m}+V_{e}\right) \\
& \theta_{s}(t)=\exp \left(\sum_{j=2}^{J} I_{j}(t) \lambda_{j s}+x^{\prime}{ }_{t} \beta_{s}+V_{s}\right) \\
& \theta_{m}(t)=\exp \left(\sum_{j=2}^{J} I_{j}(t) \lambda_{j m}+x^{\prime}{ }_{t} \beta_{m}+V_{m}\right)
\end{aligned}
$$

$I_{j}(t)$ takes on the value one if $t$ is in the interval $j . \lambda_{j e}, \lambda_{j s}$ and $\lambda_{j m}$ describe the interval specific baseline hazard rates for $J$ intervals. $I_{s}\left(t>t_{s}\right)$ and $I_{m}\left(t>t_{m}\right)$ take on the value one if $t>t_{s}$ and $t>t_{m}$, respectively. $t_{s}$ is the day of the first strong sanction, while $t_{m}$ is the day of the first mild sanction. $\alpha_{s}$ captures the effect of the first strong sanction on the transition rate into a job; $\alpha_{m}$ corresponds to effect of the first mild sanction on the hazard rate to unsubsidized employment. We assume that a sanction does not affect the transition rate before the moment of the sanction. This assumption is referred to as the no-anticipation assumption. In the case of sanctions this assumption is likely to hold, since the welfare recipient cannot anticipate the exact moment when a caseworker imposes a sanction, see Section 3. It is important to note that the individuals are allowed to know the probability distribution of future events conditional on observed and unobserved characteristics, but they are not allowed to know the exact timing of future events. Individuals might be sanctioned several times during their welfare receipt. In this 
paper, we focus on the impact of the first sanctions and ignore repeated sanctions. However, our empirical approach takes into account that some individuals might receive a strong and a mild sanction during their welfare spell. Moreover, we assume that the unobserved heterogeneity terms $V_{e}, V_{s}$ and $V_{m}$ are constant over time, and that $V_{e}, V_{s}$ and $V_{m}$ are uncorrelated with observed characteristics $x$.

\section{Distribution of the unobserved heterogeneity}

We specify the distribution of unobserved heterogeneity $G$ to have a discrete support with $M$ support points. In order to force the corresponding probabilities to be between zero and one and to sum to one, we use a multinomial logit parameterization of the class probabilities:

$$
\pi_{m}=\frac{\exp \left(\omega_{m}\right)}{\sum_{m=1}^{M} \exp \left(\omega_{m}\right)}, m=1, \ldots, M, \quad \omega_{1}=0
$$

Each of the equation specific components of the unobserved heterogeneity $V$ takes on a specific value at support point $m$. This implies that for a model with $M=2 G$ would be described by 4 parameters, for $M=3$ we estimate 8 parameters, etc. This approach allows for a flexible covariance matrix for the unobserved components. For a similar model for unobserved heterogeneity in the context of timing of events models see Crépon et al. (2013) and in the context of random coefficient models in the statistical literature see e.g. Aitkin (1999). Gaure, Roed and Zhang (2007) provide Monte Carlo evidence that modeling selection based on unobservables by a flexible discrete distribution works well in the context of timing of events models. In the estimation we increase the number of mass points until the model fit cannot be improved by a further mass point anymore, evaluated on the basis of the Akaike Criterion.

\section{Likelihood function}

Given this setup, the likelihood contribution of an individual $i$ with an observed welfare spell duration $t$ and a strong (mild) sanction imposed at $t_{s}\left(t_{m}\right)$ for given unobserved and observed characteristics $V$ and $x$ is given by:

$$
L_{i}(x, V)=\theta_{e}(t)^{\delta_{e}} S_{e}\left(t \mid x, V_{e}, t_{s}, t_{m}\right) \theta_{s}\left(t_{s}\right)^{\delta_{s}} S_{s}\left(t_{s} \mid x, V_{s}\right) \theta_{m}\left(t_{m}\right)^{\delta_{m}} S_{m}\left(t_{m} \mid x, V_{m}\right)
$$

The indicators $\delta_{e}, \delta_{s}$ and $\delta_{m}$ take on the value one if a transition to regular employment, a 
strong sanction and a mild sanction, respectively, is observed and zero otherwise. Since we do not know the unobserved characteristics for an individual $i$, the "unconditional" log-likelihood contribution corresponds to the weighted sum of the contributions corresponding to the $M$ points of support. The log-likelihood function for the sample with $N$ individuals is given by:

$$
\ln L=\sum_{i=1}^{N} \ln \sum_{m=1}^{M} \pi_{m} L_{i}(x, V(m))
$$

\section{Results}

In Table 6 we report the treatment effects for a model without (Model 1) and with (Model 2) controlling for dynamic selection based on unobserved heterogeneity. In both models we control for observed characteristics as reported in Table 5 and allow for flexible duration dependencies for the duration in welfare receipt. Moreover, we control for the month in which the welfare spell starts and include time-varying indicators for the current quarter to capture seasonal effects. Our final specification for Model 2 includes 5 support points $(M=5)$, which implies that we estimate 16 additional parameters for the distribution of unobserved characteristics compared to a model without unobserved heterogeneity. A further increase of the number of support points does not lead to further improvement of the model fit, evaluated on the basis of the Akaike Criterion.

[Table 6 about here]

In a first step we estimate a model with homogenous treatment effects. The results indicate that imposed sanctions lead to a significant increase in the transition rate from welfare to work. This holds for strong and for mild sanctions. The corresponding coefficients of the two treatment dummies are significant in the models without and with controlling for unobserved heterogeneity. However, once we control for the dynamic selection based on unobserved characteristics, the coefficients indicate a much stronger impact of imposed sanctions. The coefficients for both types of sanctions are significantly different from each other. While the coefficient for the strong sanction indicates an increase in the transition rate from welfare to 
work by around 120 percent, the imposition of a mild sanction leads to an increase in the hazard rate to unsubsidized jobs by around 37 percent.

In a second step we allow for time varying treatment effects. For this, we additionally introduce two dummy variables indicating whether the sanctions are imposed after 7 to 12 months and after more than 12 months of elapsed duration of welfare receipt, respectively. The corresponding results are reported in Table 7. None of the coefficients capturing potential timevarying effects of imposed sanctions is significantly different from zero. This suggests that imposed sanctions have the same positive impact on the hazard rate from welfare to work, independent of the timing of the imposition of the sanction.

[Table 7 about here]

Since strong sanctions involve a much larger reduction in benefit payments than mild sanctions, it is not surprising that we see a larger effect of this type of sanctions on the hazard rate to work. After all, we expect a more pronounced decrease of the reservation wage and a stronger increase of the search effort by the job seeker. However, the effect of a mild sanction is much larger than $10 \%$ of the effect of a strong sanction, while the benefits reduction in the latter case is about ten times the reduction in the former case. This suggests that part of the effect of the mild sanctions is due to the fear of intensified monitoring after the first punishment. In reality, monitoring may be intensified more strongly after a strong sanction than after a weak sanction, but this would merely reinforce our conclusion. As a caveat, notice that job search theory does not provide a justification for the assumption that the elasticity of the transition rate to work with respect to the benefits level is a constant (see e.g. van den Berg, 2001).

Overall, our results suggest that the imposition of sanctions pushes the welfare recipients to work. This suggests that sanctions help to reduce welfare dependency and to increase the employment prospects of sanctioned individuals. However, it is important to note that the quality of the jobs taken up by sanctioned and not sanctioned individuals might differ, see e.g. van den Berg and Vikström (2013) for corresponding evidence for sanctions in the unemployment insurance system in Sweden. The analysis of the impact of sanctions on job 
quality and long-term employment prospects goes beyond the scope of this paper, but it is an important dimension of the policy evaluation of sanctions in social welfare systems.

\section{Conclusions}

In this paper, we give an overview of the literature on sanctions in social welfare systems and analyze the impact of strong and mild sanctions for young welfare recipients in Germany on the hazard rate to unsubsidized employment. We use detailed administrative data and estimate timing of events models to control for selection into treatments based on unobserved characteristics.

Our results suggest that both types of sanctions lead to a higher transition rate to work, and that this effect is higher for strong sanctions. Part of the sanction effects is due to the fear of intensified monitoring after the punishment. This suggests that in the case of a first punishment during a welfare spell it is not necessary to give the maximum possible sanction, in the sense that a less strong sanction also has a strong effect on the transition rate to work while having a smaller disutility cost for the individual. This has the additional advantage that case workers with a personal bond to their clients may be less reluctant to issue a sanction if the benefits reduction is modest. The determination of the optimal size of a sanction is beyond the scope of our paper but is an interesting topic for further research.

We find that the effects of sanctions do not depend on the moment in the welfare spell that they are imposed. We did not investigate effects on post-welfare outcomes. Strong sanctions imply a complete cut of the basic cash transfer payments, and there exists evidence that severe sanctions may go along with adverse post-unemployment effects for sanctioned individuals. Therefore, future research should investigate to what extent strong sanctions for young welfare recipients lead to jobs with lower wages and with a lower future wage growth. Moreover, for the evaluation of strong sanctions for young job seekers it is important to know whether sanctioned welfare recipients have a higher probability to leave the labor force for some time, which might lead to less stable employment paths and a higher probability of welfare dependency in the future. 


\section{References}

Abbring, J.H. and G.J. van den Berg (2003): The non-parametric identification of treatment effects in duration models, Econometrica, 71, 1491-1517.

Abbring, J.H., G.J. van den Berg and J.C. van Ours (2005): The effect of unemployment insurance sanctions on the transition rate from unemployment to employment, Economic Journal, 115, 602-630.

Aitkin, M. (1999): A general maximum likelihood analysis of variance components in generalized linear models, Biometrics, 55, 117-128.

Arni, P., R. Lalive and J.C. van Ours (2013): How effective are unemployment benefit sanctions? Looking beyond unemployment exit, Journal of Applied Econometrics, forthcoming.

van den Berg, G.J. (2001), Duration models: Specification, identification, and multiple durations, in: J.J. Heckman and E. Leamer, editors, Handbook of Econometrics, Volume V, North Holland, Amsterdam.

van den Berg, G.J., B. van der Klaauw and J.C. van Ours (2004): Punitive sanctions and the transition rate from welfare to work, Journal of Labor Economics, 22, 211-241.

van den Berg, G.J., B. Hofmann and A. Uhlendorff (2013): The role of sickness in the evaluation of sanctions and job search assistance, mimeo.

van den Berg, G.J. and J. Vikström (2013): Monitoring job offer decisions, punishments, exit to work, and job quality, Scandinavian Journal of Economics, forthcoming.

Boockmann, B., S.L. Thomsen and T. Walter (2009): Intensifying the use of benefit sanctions - an effective tool to shorten welfare receipt and speed up transitions to employment, ZEW Discussion Paper 09-072.

Cockx, B., M. Dejemeppe, A. Launov and B. van der Linden (2011): Monitoring, sanctions and front-loading of job search in a non-stationary model, IZA Discussion Paper 6181.

Crépon, B., M. Ferracci, G. Jolivet and G.J. van den Berg (2013): Dynamic treatment evaluation using data on information shocks, Working Paper.

Gaure, S., K. Roed and T. Zhang (2007): Time and causality: a monte carlo assessment of the timing-of-events approach, Journal of Econometrics, 141, 1159-1195.

Götz, S., W. Ludwig-Mayerhofer, and F. Schreyer (2010): Sanktionen im SGB II: Unter dem Existenzminimum, IAB-Kurzbericht 10/2010.

Hillmann, K., and I. Hohenleitner (2012): Impact of benefit sanctions on unemployment outflow evidence from German survey data, HWWI Research Paper 129.

Hohmeyer, K. and J. Wolff (2012): A fistful of euros: Is the German one-euro job workfare scheme effective for participants? International Journal of Social Welfare, 21, 174-185.

Immervoll, H. (2009): Minimum-Income Benefits in OECD Countries: Policy Design, Effectiveness and Challenges, IZA Discussion Paper 4627.

van der Klauuw, B. and J. van Ours (2012): Carrot and stick: How re-employment bonuses and benefit sanctions affect exit rates from welfare, Journal of Applied Econometrics, forthcoming.

Lalive, R., J. van Ours and J. Zweimüller (2005): The effect of benefit sanctions on the duration of unemployment, Journal of the European Economic Association, 3, 1386-1417.

McVicar, D. and J.M. Podivinksy (2009): How well has the New Deal for Young People worked in the UK regions? Scottish Journal of Political Economy, 56, 167-195.

Nivorozhkin, A., and J. Wolff (2012): Give them a break! Did activation of young welfare recipients overshoot in Germany? (A regression discontinuity analysis), mimeo. 
Roed, K. and L. Weslie (2012): Unemployment insurance in welfare states: the impacts of soft duration constraints, Journal of the European Economic Association, 10, 518-554.

Schneider, J. (2008): The effect of unemployment benefit II sanctions on reservation Wages, IAB Discussion Paper 19/2008.

Schneider, J. (2009): Activation of welfare recipients: Impacts of selected policies on reservation wages, search effort, re-employment, and health, Ph.D. thesis, Department of Economics, Free University Berlin.

Schreyer, F., F. Zahradnik and S. Götz (2012): Lebensbedingungen und Teilhabe von jungen sanktionierten Arbeitslosen im SGB II, Sozialer Fortschritt, 61, 213-220.

Svarer M. (2011): The effect of sanctions on exit from unemployment: Evidence from Denmark, Economica, 78, 751-778.

Wolff, J. and A. Moczall (2012): Übergänge von ALG-II-Beziehern in die erste Sanktion - Frauen werden nur selten sanktioniert, IAB Research Report 11/2012. 


\section{Tables and Figures}

Table 1: Annual average stock of welfare recipients, who were capable of working, in the period under review (in Mio.)

\begin{tabular}{lcccccc}
\hline & \multicolumn{3}{c}{ All } & \multicolumn{4}{c}{ Aged below 25 years } \\
Year & 2007 & 2008 & 2009 & 2007 & 2008 & 2009 \\
\hline Germany & 5.28 & 5.01 & 4.91 & 1.04 & 0.96 & 0.91 \\
West Germany & 3.39 & 3.24 & 3.22 & 0.66 & 0.63 & 0.62 \\
East Germany & 1.88 & 1.77 & 1.68 & 0.37 & 0.33 & 0.29 \\
\hline
\end{tabular}

Source: Statistics Department of the German Federal Employment Agency

Table 2: Average share of welfare recipients with at least one sanction (stock) in the period under review (in percent)

\begin{tabular}{lccccccccc}
\hline Region & \multicolumn{3}{c}{ Germany } & \multicolumn{3}{c}{ West Germany } & \multicolumn{3}{c}{ East Germany } \\
Year & 2007 & 2008 & 2009 & 2007 & 2008 & 2009 & 2007 & 2008 & 2009 \\
\hline All & 2.4 & 2.5 & 2.5 & 2.5 & 2.7 & 2.6 & 2.1 & 2.3 & 2.3 \\
Men & 3.4 & 3.6 & 3.6 & 3.7 & 3.9 & 3.8 & 3.0 & 3.2 & 3.2 \\
Women & 1.4 & 1.5 & 1.5 & 1.5 & 1.6 & 1.6 & 1.2 & 1.3 & 1.4 \\
Aged younger than 25 years & 3.8 & 3.9 & 4.0 & 3.7 & 3.8 & 3.8 & 4.0 & 4.1 & 4.4 \\
Aged 25-49 years & 2.6 & 2.8 & 2.8 & 2.8 & 3.0 & 2.9 & 2.2 & 2.3 & 2.4 \\
Aged at least 50 years & 0.8 & 0.9 & 0.8 & 0.9 & 1.0 & 0.9 & 0.6 & 0.7 & 0.7 \\
\hline
\end{tabular}

Source: Statistics Department of the German Federal Employment Agency, own calculations

Table 3: Average number of new sanctions per welfare recipient and month in the period under review (in percent) by sanction type

\begin{tabular}{lcccccc}
\hline $\begin{array}{l}\text { Reason for } \\
\text { sanction }\end{array}$ & \multicolumn{2}{c}{$\begin{array}{l}\text { Missing an appointment } \\
\text { (relatively low benefit reduction) }\end{array}$} & \multicolumn{3}{c}{$\begin{array}{c}\text { Other reasons } \\
\text { (relatively high benefit reduction) }\end{array}$} \\
\hline Year & 2007 & 2008 & 2009 & 2007 & 2008 & 2009 \\
\hline All & 0.66 & 0.69 & 0.71 & 0.58 & 0.58 & 0.52 \\
West & 0.68 & 0.70 & 0.71 & 0.66 & 0.65 & 0.57 \\
East & 0.64 & 0.68 & 0.72 & 0.43 & 0.46 & 0.43 \\
\hline
\end{tabular}

Source: Statistics Department of the German Federal Employment Agency, own calculations

Table 4: Share of exit into strong and mild sanctions and into unsubsidized jobsa)

\begin{tabular}{lcccc}
\hline & All & $\begin{array}{c}\text { Never } \\
\text { sanctioned }\end{array}$ & $\begin{array}{c}\text { With strong } \\
\text { sanction }\end{array}$ & $\begin{array}{c}\text { With mild } \\
\text { sanction }\end{array}$ \\
\hline Share of exit into & & & & \\
- 1st strong sanction & 0,132 & 0,000 & 1,000 & 0,388 \\
- 1st weak sanction & 0,122 & 0,000 & 0,360 & 1,000 \\
- unsubsidized contributory job & 0,329 & 0,353 & 0,242 & 0,211 \\
\hline Number of spells & 71.667 & 56.888 & 9.437 & 8.735 \\
\hline
\end{tabular}

Source: Own calculations with administrative micro data

a) Contributory jobs exclude vocational training. 


\begin{tabular}{lccc}
\hline & $\begin{array}{c}\text { Never } \\
\text { sanctioned }\end{array}$ & $\begin{array}{c}\text { With strong } \\
\text { sanction }\end{array}$ & $\begin{array}{c}\text { With mild } \\
\text { sanction }\end{array}$ \\
& & & \\
\hline Number of observations & 56.888 & 9.437 & 8,735 \\
\hline Age-distribution: & & & \\
- 18 years & 0,101 & 0,149 & 0,133 \\
- 19 years & 0,117 & 0,159 & 0,146 \\
- 20 years & 0,131 & 0,150 & 0,160 \\
- 21 years & 0,137 & 0,148 & 0,154 \\
- 22 years & 0,147 & 0,156 & 0,158 \\
- 23 years & 0,170 & 0,151 & 0,148 \\
- 24 years & 0,198 & 0,087 & 0,101 \\
Family status: & & & \\
- single & 0,790 & 0,847 & 0,853 \\
- married & 0,084 & 0,038 & 0,033 \\
- not married but living with partner & 0,120 & 0,109 & 0,107 \\
- separated, widow, divorced & 0,007 & 0,005 & 0,007 \\
Nationality: & & & \\
- German & 0,802 & 0,837 & 0,830 \\
- Turkish & 0,077 & 0,070 & 0,072 \\
- other foreigner & 0,121 & 0,093 & 0,098 \\
Disability & 0,014 & 0,006 & 0,006 \\
Education: & & & \\
- no occupational degree, no schooling degree & 0,152 & 0,236 & 0,225 \\
- no occupational degree, low schooling degree & 0,407 & 0,475 & 0,470 \\
- no occupational degree, high schooling degree & 0,028 & 0,010 & 0,014 \\
- voc. training, without high schooling degree & 0,201 & 0,101 & 0,109 \\
- voc. training, high schooling degree & 0,017 & 0,004 & 0,004 \\
- technical university, university degree & 0,007 & 0,004 & 0,003 \\
- education missing & 0,188 & 0,170 & 0,175 \\
Number of own children: & & & \\
- aged less than 3 years & 0,092 & 0,077 & 0,069 \\
- aged 3 to 5 years & 0,027 & 0,020 & 0,021 \\
- aged 6 to17 years & 0,018 & 0,019 & 0,017 \\
Regularly employed in last year: & 0,449 & 0,477 & 0,520 \\
- no & 0,254 & 0,289 & 0,265 \\
- up to 1 quarter & 0,152 & 0,136 & 0,130 \\
- > 1 quarter up to 2 quarters & 0,079 & 0,060 & 0,055 \\
- > 2 quarters up to 3 quarters & & \\
\hline Table 5: Sample averages & & \\
\hline
\end{tabular}

Table 5: Sample averages of selected characteristicsa)

Source: Own calculations with administrative micro data

a) Measured at the start of their spell. 
Table 6: Baseline estimation results for the hazard rate to unsubsidized employment

\begin{tabular}{lcc}
\hline & Model 1 & Model 2 \\
\hline Strong Sanction & $0.185^{* * *}$ & $0.782^{* * *}$ \\
& $(0.022)$ & $(0.095)$ \\
Mild Sanction & $0.071^{* * *}$ & $0.312^{* * *}$ \\
& $(0.024)$ & $(0.094)$ \\
Unobserved Het. $(M=5)$ & No & Yes \\
Log-Likelihood & $-332,774.81$ & $-331,939.05$ \\
\hline
\end{tabular}

Note: Coefficients are statistically significant at the $* 10 \%,{ }^{* *} 5 \%,{ }^{* * *} 1 \%$ level. The estimation includes control variables for duration dependence, seasonal dummies, individual characteristics, and local macroeconomic conditions including the local labor unemployment rate. The complete set of coefficients for Model 2 including the distribution of the unobserved heterogeneity is reported in the Appendix in Table A.1.

Table 7: Treatment effect heterogeneity with respect to the timing of the imposed sanction

\begin{tabular}{lc}
\hline & Model 3 \\
\hline Strong Sanction & $0.702^{* * *}$ \\
& $(0.121)$ \\
Strong Sanction x 7-12 months & 0.082 \\
& $(0.080)$ \\
Strong Sanction x 13-36 months & 0.136 \\
& $(0.132)$ \\
Mild Sanction & $0.275^{* * *}$ \\
& $(0.111)$ \\
Mild Sanction x 7-12 months & -0.024 \\
Mild Sanction x 13-36 months & $0.074)$ \\
& 0.010 \\
Unobserved Het. (M=5) & $(0.124)$ \\
Log-Likelihood & Yes \\
\hline
\end{tabular}

Note: Coefficients are statistically significant at the $* 10 \%, * * 5 \%, * * * 1 \%$ level. The estimation includes control variables for duration dependence, seasonal dummies, month of entry into social welfare, individual characteristics, and local macroeconomic conditions including the local labor unemployment rate. The complete set of coefficients including the distribution of the unobserved heterogeneity is available on request. 
Figure 1: Empirical transition into the first strong punitive sanction (with 95 percent confidence band)

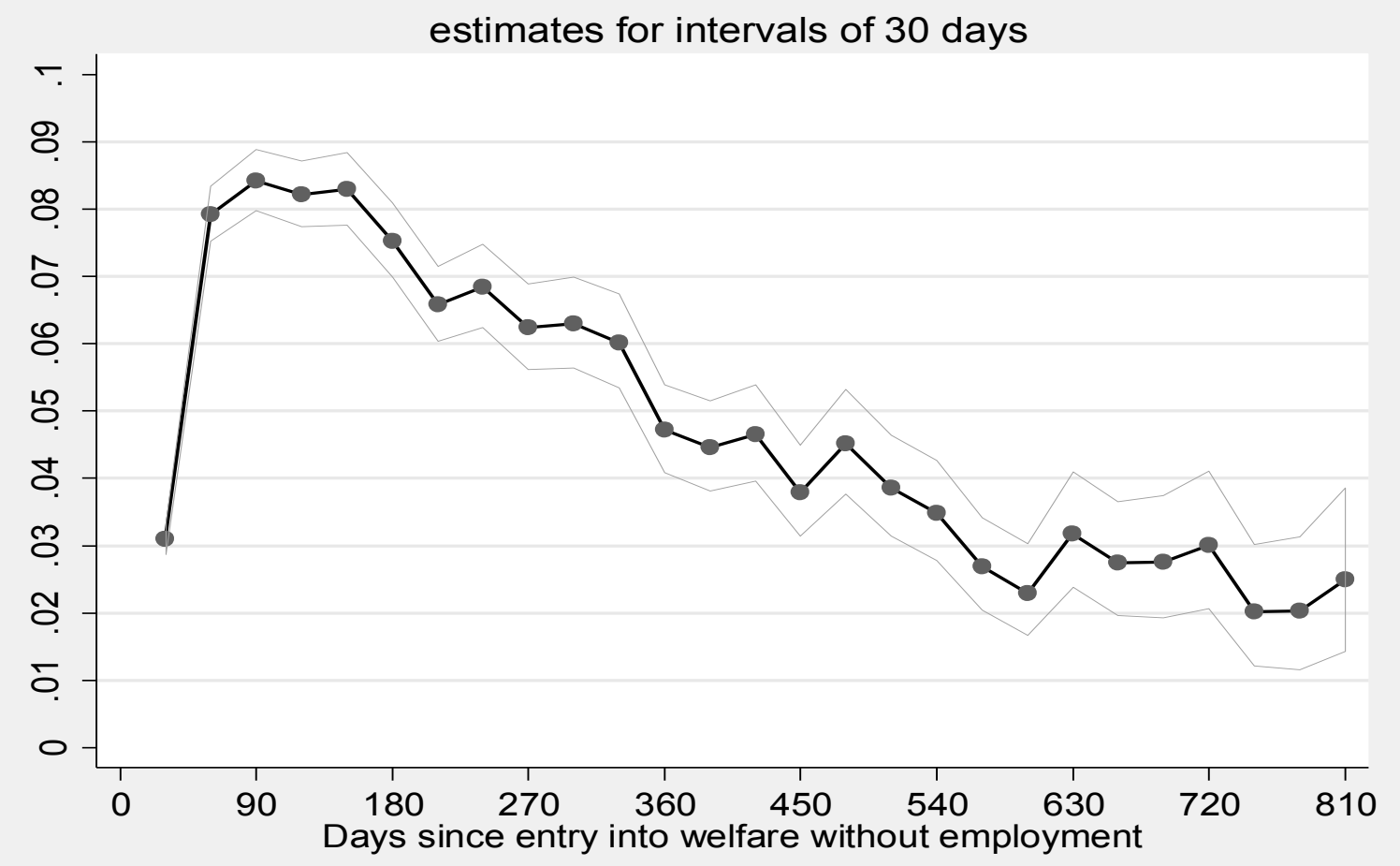

Source: Own calculations with administrative micro data 
Figure 2: Empirical transition rate into the first weak punitive sanction (with 95 percent confidence band)

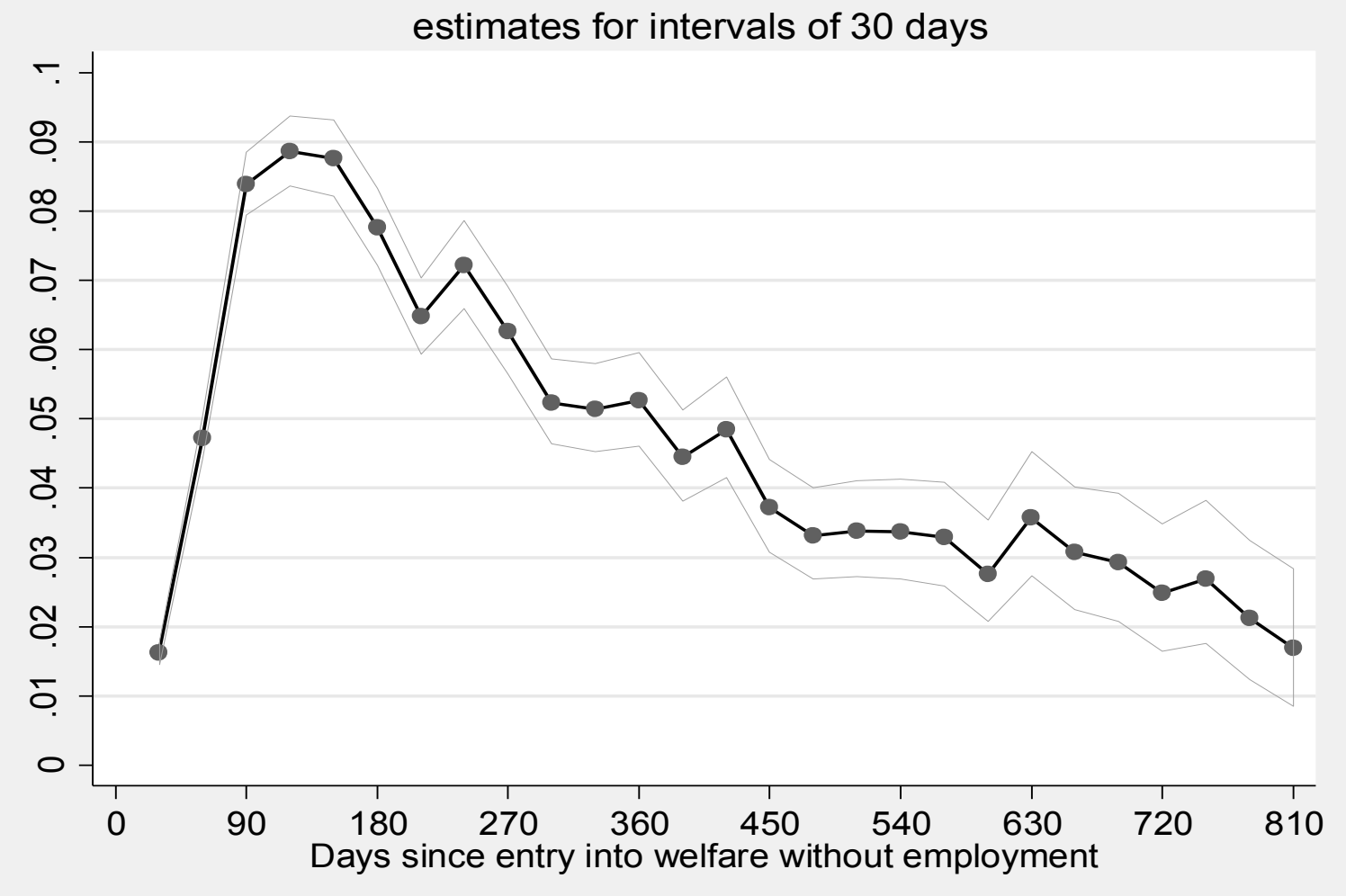

Source: Own calculations with administrative micro data 
Figure 3: Empirical transition rate into unsubsidized contributory jobs (with 95 percent confidence band)

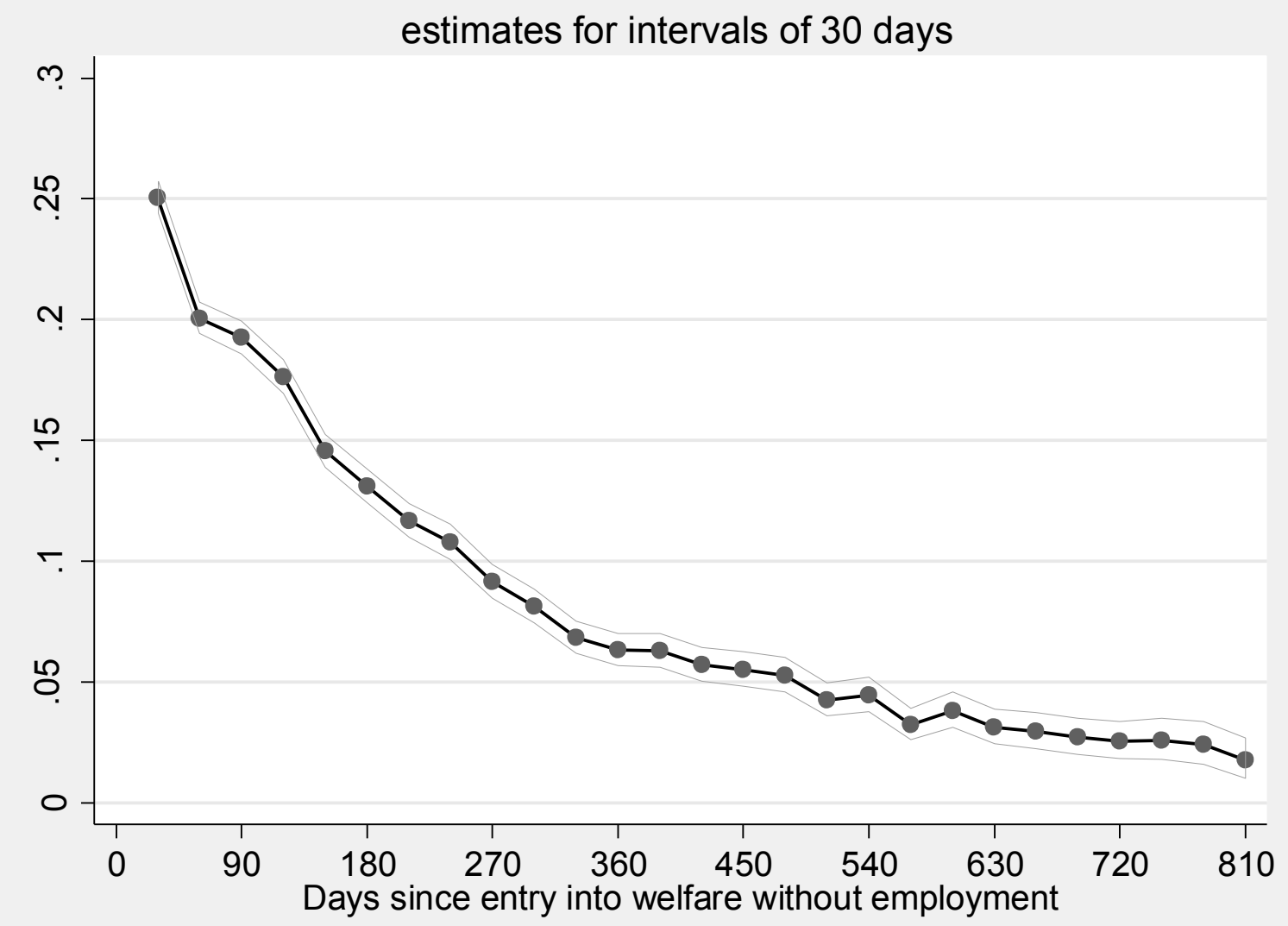

Source: Own calculations with administrative micro data 


\section{Appendix}

Table A.1: Estimation results of the baseline model with unobserved heterogeneity

\begin{tabular}{|c|c|c|c|c|c|c|}
\hline & \multicolumn{2}{|c|}{ Hazard to employment } & \multicolumn{2}{|c|}{$\begin{array}{l}\text { Hazard rate to first strong } \\
\text { sanction }\end{array}$} & \multicolumn{2}{|c|}{$\begin{array}{l}\text { Hazard rate to first mild } \\
\text { sanction }\end{array}$} \\
\hline & Coeff. & S.E. & Coeff. & S.E. & Coeff. & S.E. \\
\hline Constant & -5.130515 & 0.158080 & -6.880703 & 0.203792 & -7.216254 & 0.184075 \\
\hline Months (4-6) & -0.083919 & 0.023334 & 0.246107 & 0.028023 & 0.594404 & 0.030092 \\
\hline Months (7-9) & -0.279043 & 0.034329 & 0.157233 & 0.039584 & 0.443427 & 0.041883 \\
\hline Months (10-12) & -0.598340 & 0.045046 & 0.077548 & 0.052776 & 0.271400 & 0.055682 \\
\hline Months (13-15) & -0.696361 & 0.054301 & -0.098624 & 0.069530 & 0.160535 & 0.069454 \\
\hline Months (16-18) & -0.878425 & 0.064484 & -0.106717 & 0.084422 & -0.030784 & 0.087062 \\
\hline Months (19-21) & -1.052770 & 0.079293 & -0.401210 & 0.111219 & 0.027233 & 0.101659 \\
\hline Months $(22+)$ & -1.230289 & 0.084511 & -0.385069 & 0.117476 & -0.117241 & 0.111257 \\
\hline Strong sanction & 0.782172 & 0.094551 & - & - & - & - \\
\hline Mild sanction & 0.311632 & 0.094106 & - & - & - & - \\
\hline UE-rate & -0.028918 & 0.011435 & 0.068598 & 0.016713 & 0.097659 & 0.016696 \\
\hline Share of long-term unemployed & -0.049925 & 0.018770 & -0.175495 & 0.027678 & -0.184822 & 0.027831 \\
\hline Vacancy rate & 1.300257 & 0.122082 & -0.121874 & 0.190038 & 0.501887 & 0.193653 \\
\hline 20 years old & 0.271460 & 0.036041 & -0.371208 & 0.047387 & -0.035765 & 0.046270 \\
\hline 21 years old & 0.343946 & 0.035852 & -0.372906 & 0.047889 & -0.050034 & 0.047156 \\
\hline 22 years old & 0.369640 & 0.035984 & -0.337617 & 0.048691 & -0.044487 & 0.047711 \\
\hline 23 years old & 0.361069 & 0.035945 & -0.394205 & 0.048816 & -0.142131 & 0.048469 \\
\hline 24 years old & 0.315363 & 0.036865 & -0.456664 & 0.052593 & -0.123432 & 0.052907 \\
\hline Married & 0.569860 & 0.044840 & -0.701120 & 0.084487 & -1.004373 & 0.090916 \\
\hline Not married but living with a partner & 0.410107 & 0.036748 & -0.180760 & 0.062590 & -0.269523 & 0.064204 \\
\hline Separated, widowed, divorced & 0.316058 & 0.093308 & -0.039931 & 0.151940 & 0.142763 & 0.143225 \\
\hline Turkish nationality & 0.351525 & 0.031019 & -0.069834 & 0.047443 & -0.010066 & 0.046231 \\
\hline Other foreigner & 0.275137 & 0.025684 & -0.241262 & 0.041053 & -0.167059 & 0.040111 \\
\hline Disabled & -0.598388 & 0.081799 & -1.043968 & 0.140925 & -1.070423 & 0.149979 \\
\hline No occ. degree, no schooling & -0.974984 & 0.030245 & 0.612680 & 0.049243 & 0.419112 & 0.047844 \\
\hline No occ. degree, low schooling & -0.836541 & 0.024563 & 0.512844 & 0.043328 & 0.351232 & 0.042219 \\
\hline No occ. degree, high schooling & -0.905312 & 0.058024 & -0.464526 & 0.109652 & -0.303970 & 0.102219 \\
\hline Voc. training, no high schooling & -0.034326 & 0.065461 & -0.655787 & 0.179194 & -0.704207 & 0.179111 \\
\hline University degree & -0.888921 & 0.109175 & 0.083861 & 0.189785 & -0.231612 & 0.206156 \\
\hline Education missing & -1.066053 & 0.032631 & 0.044950 & 0.052843 & 0.066901 & 0.053210 \\
\hline No. of children between 6-17 years & -0.091246 & 0.050606 & 0.076187 & 0.077220 & 0.084351 & 0.083071 \\
\hline Partner younger than 20 & -0.156885 & 0.046080 & 0.100165 & 0.076811 & 0.135341 & 0.077171 \\
\hline Partner between 25-29 years & 0.036150 & 0.048532 & -0.094228 & 0.094973 & -0.106401 & 0.099005 \\
\hline Partner between $30-34$ years & -0.232888 & 0.114819 & -0.009697 & 0.188350 & -0.521382 & 0.227006 \\
\hline Partner older than 34 years & 0.037653 & 0.141078 & 0.234258 & 0.269624 & 0.060685 & 0.286221 \\
\hline Partner foreigner & -0.146464 & 0.045723 & 0.002087 & 0.084725 & 0.013801 & 0.089221 \\
\hline Partner no occ. degree, no schooling & -0.080288 & 0.058435 & 0.222546 & 0.096258 & 0.272048 & 0.097745 \\
\hline Partner no occ. degree, low schooling & 0.123997 & 0.041032 & 0.046355 & 0.074059 & 0.060349 & 0.075810 \\
\hline Partner no occ. degree, high schooling & 0.087996 & 0.113328 & -0.351585 & 0.238024 & -0.344974 & 0.271434 \\
\hline Partner education missing value & -0.079421 & 0.049024 & 0.037398 & 0.089641 & 0.135388 & 0.090826 \\
\hline \multicolumn{7}{|l|}{ Unobserved Heterogeneity } \\
\hline $\mathrm{V} 2$ & 1.272058 & 0.213185 & -3.517990 & 4.065140 & -3.267671 & 3.420475 \\
\hline V3 & -2.295400 & 0.145296 & 0.691409 & 0.236896 & 0.234630 & 0.217350 \\
\hline V4 & -0.153988 & 0.577736 & -2.633537 & 1.947935 & -1.783316 & 0.667200 \\
\hline V5 & -1.397236 & 0.516297 & -1.146243 & 0.568552 & -1.562899 & 0.478757 \\
\hline$\omega_{2}$ & -0.777491 & 0.416161 & & & & \\
\hline$\omega_{3}$ & -0.456368 & 0.336561 & & & & \\
\hline$\omega_{4}$ & -0.131856 & 0.662975 & & & & \\
\hline$\omega_{5}$ & -0.158201 & 0.653638 & & & & \\
\hline
\end{tabular}

Note: The estimation additionally includes month of entry into social welfare and dummies for the different counties (Bundesländer). 